International

Medical Society

http://imedicalsociety.org

\title{
Neurological Assessment and Degree of Disability of Leprosy Patients: Observation at Diagnosis and at Discharge
}

\begin{abstract}
Carla Andréa Avelar Pires ${ }^{1}$, Sabrina Sampaio Bandeira ${ }^{2}$, Gabriela Ferreira Rocha1, Marcella Silva Maia1, Ana Carolina Magalhães Nascimento1, Márcia Moraes dos Prazeres ${ }^{1}$, Suzana Maria Klautau Ferreira1, Anderson Phelipe Dias Sabry Azar', Heraldo Hebert Mauro Neto1, Rafael Oliveira Chaves', Adriana Kamilly Leitão Pitman Machado ${ }^{1}$
\end{abstract}

\section{Abstract}

Background: Caring for leprosy patients requires neurological assessment for prevention of potential physical disabilities. This study focused on the neurological impairment and degree of physical incapacity (DI) at the time of the diagnosis and at discharge of leprosy patients from Dermatology Department of the University of the State of Pará.

Methods and Findings: It was a cross-sectional, observational study based on the medical records, neurological assessment and DI of 14 patients assisted at a referral service between 2012 and 2016, applying descriptive statistical analysis. At diagnosis were observed patients with decreased abduction forces of the 5th finger (14.28\%), extension of hallux and foot dorsiflexion (10.72\%); loss of protective sensitivity in the ulnar nerve area (3.57\%) and tibial nerve area (25\%); $7.15 \%$ of thickened ulnar nerve; DI 0 (64.28\%) and DI 1 (35.72\%). At discharge, $10.72 \%$ of the patients showed decreased abduction of the 5th finger, extension of hallux and foot dorsiflexion (14.28\%); loss of protective sensitivity just in the tibial nerve area (17.87\%); $4.28 \%$ of thickened ulnar nerve; DI 0 (78.57\%) and DI 1 (21.43\%).

Conclusions: Therefore, most of the patients had normal neurological assessment and DI 0 at both moments, with reduction of altera-
1 Universidade do Estado do Pará. Belém, Pará, Brazil.

2 Unidade de Referência em Dermatologia Sanitária Marcello Cândia. Marituba, Pará, Brazil.

Contact information:

\section{Gabriela Ferreira Rocha.}

Address: Universidade do Estado do Pará. Travessa Perebebuí, n²623, Belém. 66095-450 (Brazil).

झ gabyfr10@yahoo.com.br. 
tions in discharge, except for the fibular nerve. Thus, it is highlighted the primary role of the health team, which constitutes one of the main agents promoters of health education, especially when it comes to preventing disabilities in leprosy

\section{Keywords}

Leprosy; Neuritis; Complications; Self Care.

\section{Introduction}

Historically known and stigmatized, leprosy is still present in the 21st century, with more than 200.000 new cases detected in the world in 2014 [1] and more than 28.000 in 2015 just in Brazil. Currently, the country ranks second in the world ranking of prevalence and incidence. The Central-West, North and Northeast regions concentrate the majority of the cases, focusing on the State of Pará, with the fourth highest overall detection rate of new cases [2].

Neurological assessment aims to detect early changes caused by leprosy. For this, it is essential the correct training of all the health team for the accomplishment of an effective evaluation, following the same pattern, aiming fundamentally at the prevention of the incapacities resulting from the leprosy neuropathy [3].

\section{Methods}

This was a cross-sectional, observational and descriptive study using medical records, neurological assessment and degree of physical incapacity (DI) [4] of 14 leprosy patients from the Dermatology Department of the University of the State of Pará and with discharge at polychemotherapy (MDT) between January 2012 and January 2016. The research was approved by the Research Ethics Committee at the UEPA and the free and informed consent form was signed by the participant patients. Social and demographic information and clinical form of leprosy were collected from the medical records (according to the Madrid classification [5] and operational classification [6]). From neurological assessment and DI records were verified muscle strength (if strong, diminished or paralyzed), mapping of hand, eye and foot sensitivity and palpation of the ulnar, medial, radial, fibular and posterior tibial nerves, at diagnosis and at discharge from MDT.

Hand sensitivity was considered as preserved when there was a tactile perception by the individual of the green monofilament $(0.05 \mathrm{~g})$. The sensitivity of the hands was considered to be diminished when there was a tactile perception only from the monofilaments blue $(0.2 \mathrm{~g})$ or lilac $(2 \mathrm{~g})$. In the feet area, the perception of the monofilaments green $(0.05 \mathrm{~g})$ or blue $(0.2 \mathrm{~g})$ was considered preserved and diminished when was recorded the perception of the monofilament lilac (2g). Preserved protective sensitivity was considered when it was demonstrated tactile perception of green, blue or lilac monofilaments in feet and/or hands. In cases of tactile perception only from the closed red monofilament in feet and/or hands, the protective sensitivity was considered as lost [4].

The degree of disability was determined from the neurological assessment of the eyes, hands and feet and its result expressed in values ranging from 0 (zero) to 2 (two), where: degree 0 - No problem with eyes, hands and feet due to leprosy; degree 
1 - Decreased or lost sensitivity in the eyes and/or decreased or lost sensitivity in the hands/feet (do not feel $2 \mathrm{~g}$ or pen touch); degree 2 - Eyes: lagophthalmus and/or ectropion; trichiasis; central corneal opacity; visual acuity less than 0.1 or do not count fingers at $6 \mathrm{~m} /$ Hands: trophic lesions and/or traumatic lesions; claws; reabsorption; fallen hand/ Feet: trophic and/or traumatic lesions; claws; reabsorption; foot drop; ankle contraction [4].

BioEstat 4.5 software was used for descriptive statistical analysis.

\section{Results}

Regarding the social and demographic characteristics, the sample consisted of $57.15 \%$ of males, with clinical forms multibacillary (71.42\%) and dimorphic (57.16\%). At diagnosis, $7.15 \%$ of the ulnar nerves were thickened on palpation. In the evaluation of muscle strength at diagnosis, according to Table 1, $85.72 \%$ of the patients had preserved abduction of the 5 th finger of the hand and $14.28 \%$ was diminished; $89.28 \%$ had preserved foot extension and preserved foot dorsiflexion and $10.72 \%$ had this function diminished. Regarding the sensitivity evaluation at diagnosis, according to Table 2, 64.28\% of the sensitivity in the ulnar nerve area was preserved and $35.72 \%$ was reduced; $71.43 \%$ of the sensitivity in the tibial nerve area was preserved and $28.57 \%$ was reduced.

Regarding DI at diagnosis, according to Figure 1, it was identified that $64.28 \%$ of the patients had DI 0 and $35.72 \%$ DI 1. During the evaluation at discharge, $4.28 \%$ of the ulnar nerves were thickened on palpation. Regarding muscle strength, $89.28 \%$ of the patients had preserved abduction of the $5^{\text {th }}$ finger of the hand and in $10.72 \%$ of the patients this function was diminished; $85.72 \%$ had preserved foot extension and preserved foot dorsiflexion and $14.28 \%$ of the patients had this function diminished. In the evaluation of sensitivity, $64.28 \%$ of the patients had preserved sen-
Table 1. Evaluation of muscle strength at the diagnosis and at discharge of leprosy patients.

\begin{tabular}{|l|c|c|c|c|}
\hline \multirow{2}{*}{ Muscle strenght } & \multicolumn{2}{|c|}{ Diagnosis } & \multicolumn{2}{c|}{ Discharge } \\
\cline { 2 - 5 } & $\mathrm{N}^{\circ}$ & $\%$ & $\mathrm{~N}^{\circ}$ & $\%$ \\
\hline $\begin{array}{l}\text { Abduction of the 5th finger of the right and left hands } \\
\text { (ulnar nerve) }\end{array}$ & 24 & 85.72 & 25 & 89.28 \\
\hline Strong & 4 & 14.28 & 3 & 10.72 \\
\hline Diminished & - & - & - & - \\
\hline Paralysed & 28 & 100.00 & 28 & 100.00 \\
\hline Total
\end{tabular}

Abduction of the thumb of the right and left hands (median nerve)

\begin{tabular}{|l|c|c|c|c|}
\hline Strong & 25 & 89.28 & 26 & 92.85 \\
\hline Diminished & 3 & 10.72 & 2 & 7.15 \\
\hline Paralysed & - & - & - & - \\
\hline Total & 28 & 100.00 & 28 & 100.00 \\
\hline
\end{tabular}

Extension of right and left wrists (radial nerve)

\begin{tabular}{|l|c|c|c|c|}
\hline Strong & 25 & 89.28 & 26 & 92.85 \\
\hline Diminished & 3 & 10.72 & 2 & 7.15 \\
\hline Paralysed & - & - & - & - \\
\hline Total & 28 & 100.00 & 28 & 100.00 \\
\hline
\end{tabular}

Extension of right and left hallux (fibular nerve)

\begin{tabular}{|l|c|c|c|c|}
\hline Strong & 25 & 89.28 & 24 & 85.72 \\
\hline Diminished & 3 & 10.72 & 4 & 14.28 \\
\hline Paralysed & - & - & - & - \\
\hline Total & 28 & 100.00 & 28 & 100.00 \\
\hline
\end{tabular}

Dorsiflexion of the right and left foot (fibular nerve)

\begin{tabular}{|l|c|c|c|c|}
\hline Strong & 25 & 89.28 & 24 & 85.72 \\
\hline Diminished & 3 & 10.72 & 4 & 14.28 \\
\hline Paralysed & - & - & - & - \\
\hline Total & 28 & 100.00 & 28 & 100.00 \\
\hline
\end{tabular}

Table 2. Sensitivity evaluation with Semmes-Weinstein monofilaments performed at the diagnosis and at discharge of leprosy patients.

\begin{tabular}{l|c|c|c|c|}
\hline \multirow{2}{*}{ Monofilaments } & \multicolumn{2}{|c|}{ Diagnosis } & \multicolumn{2}{c|}{ Discharge } \\
\cline { 2 - 6 } & \multicolumn{2}{|c|}{$N^{\circ}$} & $\%$ & \multicolumn{2}{c|}{$N^{\circ}$} & $\%$ \\
\hline Hand area innervated by the ulnar nerve \\
\hline Green & 18 & 64.28 & 18 & 64.28 \\
\hline Blue & 9 & 32.15 & 8 & 28.57 \\
\hline
\end{tabular}




\begin{tabular}{|c|c|c|c|c|}
\hline \multirow{2}{*}{ Monofilaments } & \multicolumn{2}{|c|}{ Diagnosis } & \multicolumn{2}{|c|}{ Discharge } \\
\hline & $\mathrm{N}^{\circ}$ & $\%$ & $\mathrm{~N}^{0}$ & $\%$ \\
\hline \multicolumn{5}{|c|}{ Hand area innervated by the ulnar nerve } \\
\hline Purple & - & - & 2 & 7.15 \\
\hline Red & 1 & 3.57 & - & - \\
\hline Black & - & - & - & - \\
\hline Total & 28 & 100.00 & 28 & 100.00 \\
\hline \multicolumn{5}{|c|}{ Hand area innervated by the median nerve } \\
\hline Green & 19 & 67.85 & 19 & 67.85 \\
\hline Blue & 6 & 21.43 & 7 & 25.00 \\
\hline Purple & 3 & 10.72 & 2 & 7.15 \\
\hline Red & - & - & - & - \\
\hline Black & - & - & - & - \\
\hline Total & 28 & 100.00 & 28 & 100.00 \\
\hline \multicolumn{5}{|c|}{ Sole of the foot (tibial nerve) } \\
\hline Green & 11 & 39.28 & 15 & 53.56 \\
\hline Blue & 9 & 32.15 & 5 & 17.85 \\
\hline Purple & 1 & 3.57 & 3 & 10.72 \\
\hline Red & 3 & 10.72 & 2 & 7.15 \\
\hline Black & 4 & 14.28 & 3 & 10.72 \\
\hline Total & 28 & 100.00 & 28 & 100.00 \\
\hline
\end{tabular}

Figure 1: Degree of disability evaluated at diagnosis and at discharge of leprosy patients.

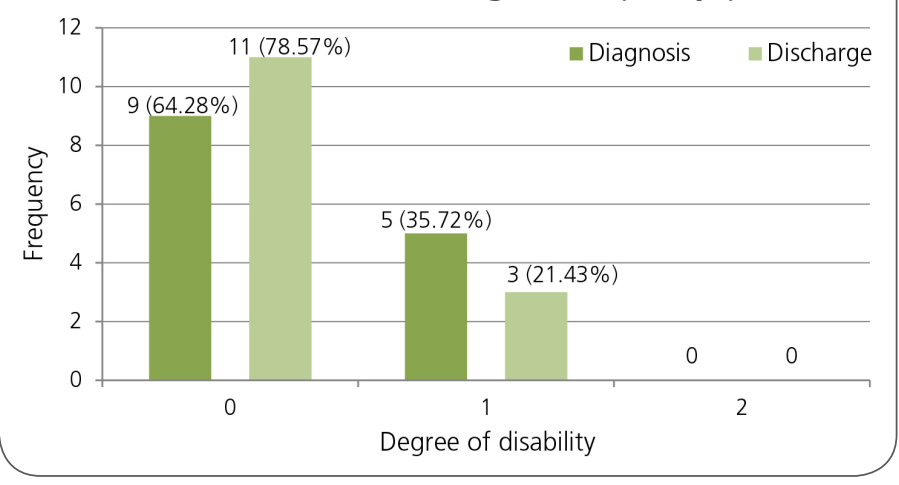

sitivity in the area of the ulnar nerve and 35.72\% had reduced sensitivity in this area; $71.41 \%$ had preserved sensitivity in the tibial nerve area and $28.59 \%$ had reduced sensitivity in this area. It was found a percentage of $78.57 \%$ of DI 0 and $21.43 \%$ of DI 1 at the discharge.

\section{Discussion}

Leprosy is one of the most alarming public health problems in Brazil nowadays, placing the country second in the world ranking of endemicity of the disease [1]. In view of this, strategies to reduce the burden of disease involve, primarily, health education coupled with effective epidemiological surveillance, prevention and treatment of disabilities, with regular neurological assessments and treatment to cure [2].

Analyzing the socio-demographic profile of the patients, a discrete male predominance was observed over the female. Such a finding may indicate a slightly more pronounced exposure of adult men to the triggering factors of leprosy, explaining their greater involvement and, thus, greater demand for health services. This result agrees with DATASUS data [7] which shows that the number of men carrying the disease surpasses the number of women in most Brazilian states.

Timely diagnosis is essential for the breakdown of the epidemiological chain of transmission of the disease, since it allows the identification of individuals with high bacilliferous load, which are the main sources of infection responsible for maintaining the endemic of leprosy. In this sense, the health service where the current study was conducted showed an important participation in the detection and breakdown of the transmission cycle, since the most diagnosed leprosy population was multibacillary, in keeping with the generally still endemic situation in the Northern region of Brazil.

The greatest number of multibacillary cases, especially in regions with difficult disease control, is also reported in the literature. According to the World Health Organization [8] there is a worldwide prevalence of multibacillary forms, especially in the African and American continents, which still face the problems of extreme social inequality and poverty.

In this study, even in front of the presence of a greater number of nerves without alteration on 
palpation at diagnosis and at discharge, a considerable number of nerves were thickened at the both moments, especially the ulnar nerve. Then, this result should be considered as worrisome, since, according to Monteiro [9], thickening leads to partial nerve ischemia and, if the process continues, to total paralysis.

Among the small number of patients that presented altered muscle strength, a predominance of a decrease in the abduction strenght of the 5th finger of the hand, attributed to the ulnar nerve, was observed at the diagnosis. This result was expected because, according to Mesquita et al [3], the ulnar and median nerves are the most commonly affected by compressive syndromes leprosy-related.

During the observation at discharge, among the patients whose strength muscle was diminished, there was reduction of the paresis of the ulnar nerve, but growth of the number of paresis of the hallux extension and foot dorsiflexion, under the responsibility of the fibular nerve, when compared to the diagnosis. This result suggests the need for reinforcement in the surveillance of post-discharge of the MDT patients by the health team, since nerve involvement in question can lead to deformities such as "fallen foot" or "equine foot" [10].

In addition to muscle strength, another important evaluation to be performed regularly is the sensitivity of hands and feet in order to detect minimal sensitivity changes and seek timely conduct for the maintenance of protective sensitivity. In the current study, there was a predominance of normal sensitivity in the hands and feet both in diagnosis and in patients' discharge. When these regions were examined separately, there was a reduction in sensitivity and loss of protective sensitivity of the plantar region of the foot, innervated by the tibial nerve, in both moments. This was expected because, according to Tavares et al [11], the main nerve affected by the bacillus is the posterior tibial.
At discharge, it was verified an improvement in the sensitivity of the feet, probably due to the good therapeutic adherence and adequate treatment of the eventual leprosy reactions. However, there were still nerves with loss of protective sensitivity of this area, which could evolve with complications in the post-discharge period. In the evaluation of the upper limbs, a considerable decrease of the sensitivity in the areas of the ulnar and median nerves in the diagnosis and the discharge was found. It was also observed that the ulnar nerve was the only one of the upper limb with loss of protective sensitivity at diagnosis, but it improved at discharge, as the patient noticed the monofilament lilac instead of the closed red. The sensitivity of the area innervated by the median nerve also evolved to improvement, from the tactile perception of monofilament lilac to blue. According to the Ministry of Health of Brazil [4], the sensitive involvement of the upper limbs usually begins by the ulnar nerve, followed by the median and radial nerves, confirming the findings of the present study. One of the most worrying factors of leprosy, as already emphasized, is its disabling potential. In view of this, the gaze that was previously directed especially to the breakdown of the chain of transmission of the disease, began to focus on the issues related to the incapacities resulting from it $[12,13]$. The present study found a higher prevalence of the degree of physical incapacity zero ( $D I 0$ ) in both periods studied, especially the increase of the number of patients under these conditions at discharge. This reinforces the already exposed findings of neurological preservation of the hands, feet and eyes. These results may be a reflection of the active participation and the assistance of health professionals, who play a fundamental role in the search for early signs of physical incapacity and patient orientation about their risks.

In addition, none patient presented DI 2 in any moment studied. However, a considerable amount of DI 1 was found at diagnosis, with a reduction 
of these at discharge. It is worth mentioning that the alteration of sensitivity is the main responsible for the emergence of disabilities found in DI 1, evidencing the importance of the guidelines regarding the prevention of ulcers and trophic lesions by the professionals of the area [12].

\section{Conclusion}

Leprosy patients attended at the Dermatology Service of the University of the State of Pará were predominantly male. They had predominantly the multibacillary dimorphic form. Most of the patients did not present sensory-motor alterations in the neurological assessment at diagnosis and discharge, with DI 0. However, among the sample that presented an altered neurological assessment, neurological impairment was characterized by the thickening of the ulnar nerve at the palpation; decrease of the abduction force of the 5th finger of the hand (ulnar nerve), as well as reduction of the sensitivity of the plantar region of the foot (tibial nerve) and the area of the hand innervated by the ulnar and median nerves. Besides that, there was loss of protective sensitivity in the areas of the ulnar and posterior tibial nerves and a considerable number of DI 1 at diagnosis. At discharge, these findings were improved, with the exception of the muscle strength of the hallux and dorsiflexion of the foot, which showed worsening. Thus, it is highlighted the primary role of the health team, which constitutes one of the main agents promoters of health education, especially when it comes to preventing disabilities in leprosy.

\section{Acknowledgments}

We are grateful for the allowed of the patients attended in the Dermatology Department of the University of the State of Pará to collect their data in this service.

\section{Fundings}

The authors declare having had no financial support.

\section{Conflict of interest disclosures}

The authors declare that there are no conflicts of interest in this study.

\section{Contribution}

Gabriela Rocha, Marcella Maia, Ana Carolina Nascimento, Márcia dos Prazeres, Suzana Ferreira, Anderson Azar, Heraldo Neto, Rafael Chaves, Adriana Machado: review of literature, data collect, interpretation of data, writing and concept of the manuscript.

Carla Pires, Sabrina Bandeira: Concept and orientation of the manuscript, obtaining data and methodological review of the manuscript.

\section{References}

1. World Health Organization. Weekly epidemiological record. 2015; (36): 461-76.

2. Ministério da Saúde. Diretrizes para vigilância, atenção e eliminação da hanseníase como problema de saúde pública: manual técnico-operacional. 2016. [Internet]. Brasília: Brasil; 2016. [citado em 2017 dez 19] Available in: http://portalsaude. saude.gov.br/images/pdf/2016/fevereiro/04/diretrizeseliminacao-hanseniase-4fev16-web.pdf.

3. Mesquita R. et al. Avaliação neurofuncional em pacientes com Hanseníase. Rev Bras Promoç Saúde. 2014; 27 (2): 247-55.

4. Ministério da Saúde. Secretaria de Vigilância em Saúde. Departamento de Vigilância Epidemiológica. Manual de Prevenção de Incapacidades. 2008. [Internet]. Brasília; 2008. [citado em 2017 dez 19] Available in: http://portalsaude. saude.gov.br/index.php/o-ministerio/principal/leia-mais-oministerio/707-secretaria-svs/vigilancia-de-a-a-z/hanseniase//2hanseniase/13717-publicacoes-hanseniase

5. Basombrio, G. et al. Draft report of classification Committee. In: Congresso Internacional de Leprologia; 1953; Madrid: Associación Internacional de la Lepra; 1953. p. 75- 86.

6. World Health Organization. Chemotherapy of leprosy for control programmes: report of a WHO study group. 1982; (675).

7. DATASUS. Taxa incidência de hanseníase segundo Sexo Período. 2012. [Internet]. Available in: http://tabnet.datasus.gov. br/cgi/tabcgi.exe?idb2012/d0206.def.. 
8. World Health Organization. Global leprosy update, 2013; disease burden. Weekly epidemiological Record. 2014; 89 (36): 389-400.

9. Monteiro LD. Padrões de comprometimento neural, limitação de atividade, participação social e fatores associados nas pessoas em pós alta da hanseníase nos anos de 2004 a 2009, Araguaína- TO. [Dissertation- Master in Health Public]. Fortaleza (CE): Universidade Federal do Ceará, 2012.

10. Virmond $\mathrm{MCL}$, Cury Filho M. Tratamento cirúrgico nos membros superiores e inferiores. In: Alves ED, Ferreira TL, Ferreira IN. Hanseníase: avanços e desafios. 1. ${ }^{a}$ ed. Brasília: NESPROM- Unb, 2014. p. 305-332.

11. Tavares JP et al. Fisioterapia no atendimento de pacientes com hanseníase: um estudo de revisão. Rev. amazônia: science \& health. 2013; 1(2):37-43.

12. Brandão, JG. Incapacidade física durante o tratamento poliquimioterápico dos pacientes de hanseníase no Brasil nas coortes de cura de casos novos dos anos de 2010 e 2011. [Dissertation -Master in Health Science]. Brasília (DF): Universidade de Brasília, 2013.

13. Borges MGL et al. O cuidado hospitalar na hanseníase: um perfil do Estado do Pará de 2008 a 2014. Rev. Hansen. Int.. 2015; 40(1): 25-32.

\section{Publish in International Archives of Medicine}

International Archives of Medicine is an open access journal publishing articles encompassing all aspects of medical science and clinical practice. IAM is considered a megajournal with independent sections on all areas of medicine. IAM is a really international journal with authors and board members from all around the world. The journal is widely indexed and classified Q2 in category Medicine. 